\title{
Campo alimentario: lógicas de la práctica alimentaria entre trabajadores agrícolas en Miguel Alemán, Sonora, México
}

\author{
Food Field: Rationales of Food Practice among \\ Agricultural Workers in Miguel Alemán, Sonora, Mexico
}

\author{
María del Carmen Arellano Gálvez* (D) http://orcid.org/0000-0001-9951-6960 \\ Guadalupe del Carmen Alvarez Gordillo** (D) https://orcid.org/0000-0002-9543-7920 \\ Enrique Eroza Solana ${ }^{* * *}$ (D) https://orcid.org/0000-0002-1430-6022 \\ Esperanza Tuñón Pablos ${ }^{* * * *}$ (i) https://orcid.org/0000-0002-1269-6928
}

\begin{abstract}
Resumen
El objetivo de esta investigación cualitativa es analizar las lógicas que operan en el campo alimentario entre trabajadores agrícolas migrantes en Miguel Alemán, Sonora, México. Se realizaron observaciones, entrevistas y análisis documental y periodístico. Los resultados visibilizan las prácticas de autoconsumo como estrategias frente al mercado, mientras que las personas consumen alimentos en la lógica de lo posible. Los programas de alimentación gratuita reflejan pobreza alimentaria que, sumada a la violencia social, condiciona la práctica alimentaria. La limitante fue no contar con información de migrantes que viven en los campos agrícolas. La originalidad radica en que se utilizó el enfoque teórico de Bourdieu, para analizar la alimentación en población vulnerada. Se concluye que examinar el campo alimentario permite comprender el sentido lógico de la práctica, al desnaturalizar las decisiones alimentarias como asunto individual, e identificar los capitales que estructuran la práctica alimentaria y las situaciones que la vulneran, entre trabajadores agrícolas migrantes.

Palabras clave: alimentación; práctica alimentaria; trabajadores agrícolas migratorios; migración rural; Sonora.
\end{abstract}

\begin{abstract}
The objective of this qualitative research is to analyze the rationales operating in the food field among migrant agricultural workers in Miguel Alemán, Sonora, Mexico. Observations, interviews and documentary and journalistic analysis were made. The results highlight self-consumption practices as strategies against the market, while people consume food according to the logic of what is possible. Free food programs reflect food poverty, which, in addition to social violence, conditions food practice. This research's limitation was not having information on migrants living in agricultural fields. Its originality lies in the fact that Bourdieu's theoretical approach was used to analyze the feeding of the affected population. It is concluded that examining the food field allows us to understand the logical meaning of the practice, by denaturing food decisions as an individual issue, and to identify the capitals that structure food practice and the situations that affect it, among migrant agricultural workers.

Keywords: feeding; food practice; migrant agricultural workers; rural migration; Sonora.
\end{abstract}

Cómo citar:Arellano Gálvez, M. C., Alvarez Gordillo, G. C., Eroza Solana, E., y Tuñón Pablos, E. (2019). Campo alimentario: lógicas de la práctica alimentaria entre trabajadores agrícolas en Miguel Alemán, Sonora, México. región y sociedad, 31, e I |43. doi: I0.22 I 98/rys20 I 9/3 |/ | |43

* Autora para correspondencia. El Colegio de la Frontera Sur. Carretera Panamericana y Periférico s/n, barrio María Auxiliadora, C. P. 29290 , San Cristóbal de Las Casas, Chiapas, México. Teléfono: (976) 674 9000. Correo electrónico: mcarellano@ecosur.edu.mx

** El Colegio de la Frontera Sur. Carretera Panamericana y Periférico s/n, barrio María Auxiliadora, C. P. 29290,

San Cristóbal de Las Casas, Chiapas, México. Teléfono: (976) 674 9000. Correo electrónico: galvarez@ecosur.mx

*** Centro de Investigaciones y Estudios Superiores en Antropología Social Unidad Sureste. Las Peras, San Martín, C. P. 29247,

San Cristóbal de las Casas, Chiapas, México. Teléfono: (967) 674 9000. Correo electrónico: enriquesol@yahoo.com

**** El Colegio de la Frontera Sur. Carretera Panamericana y Periférico s/n, Barrio María Auxiliadora, C. P. 29290,

San Cristóbal de Las Casas, Chiapas, México. Teléfono (976) 674 9000. Correo electrónico: etunon@ecosur.mx

Recibido: 11 de octubre de 2018

Aceptado: 1 de febrero de 2018

Liberado: 14 de agosto de 2019

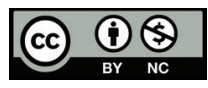

Esta obra está protegida bajo una Licencia Creative Commons Atribución-No Comercial 4.0 Internacional. 


\section{Introducción}

Diversos procesos sociales, económicos, geográficos y políticos confluyeron para que, desde mediados del siglo XX, el noroeste de México se convirtiera en polo de atracción para campesinos del sur-sureste mexicano, quienes emigraron y continúan haciéndolo para emplearse en las agroindustrias de exportación del país (Barros, 2015; Bautista, 2017; Chong, Herrera, Chávez y Sánchez, 2015; Durand, 2017; Escobar, Martin, Lowell y Fernández 2013; Gonzalez, 2016; Holmes, 2013; Izcara, 2014; Lara, 2010). Gracias a la mano de obra de este sector productivo, los empresarios obtienen capital económico, y construyen el mercado de trabajo según la premisa de reducción de costos de producción (Posadas, 2018). Esto se traduce en salarios bajos para trabajadores/as agrícolas, situación provocada por los vacíos jurídicos para que esta población tenga acceso y ejerza sus derechos laborales, sociales y de salud, lo que la ubica en una posición subordinada en la cadena de producción global (Aranda y Castro, 2016; Hernández, 2014; Valdivia y Sánchez, 2017; Valdés, 2015).

Las condiciones del proceso migratorio y del trabajo agrícola reflejan las múltiples desigualdades que viven los jornaleros (Espinoza, Ramírez y Tello, 2017; Grammont y Lara, 2004; Lara, 2012; Ortega, Castañeda y Sariego, 2007; Velasco, 2013; Velasco, Zlolniski y Coubès, 2014), que empiezan en los lugares de origen, en donde tanto lo que se produce para el autoconsumo y los sistemas locales de producción ya son insostenibles frente al mercado alimentario globalizado (Delgado, 2010). Sin embargo, las personas que se emplean como trabajadores agrícolas no terminan con la precariedad y la circularidad de la pobreza (Rojas, 2017), quedan excluidos de una vida digna, al punto de comprometer su alimentación, necesidad básica y derecho humano que se traduce en malnutrición que provoca efectos diversos en su salud (Castañeda, 2017; Ortega et al., 2012, 2008). Es paradójico que con su trabajo, ellos favorezcan que alimentos de primera calidad se oferten en el mercado, pero no puedan consumirlos.

El objetivo de este artículo es analizar las lógicas que operan en el campo alimentario entre trabajadores agrícolas migrantes en Miguel Alemán, Sonora, México. ${ }^{1}$ Se partió del enfoque teórico de Bourdieu para comprender las relaciones que posibilitan ciertas prácticas alimentarias entre trabajadores/as agrícolas, al desnaturalizarlas como decisiones individuales, y contextualizarlas en las desigualdades que impiden el acceso a los alimentos, vinculadas con sus precarias condiciones de vida tanto materiales como simbólicas, y ubicarlos en una posición social subordinada. Algunos estudios desde este marco teórico analizan la relación entre prácticas alimentarias, clase social y capital como mecanismos de diferenciación social (Atkins y Bowler, 2016; Beagan, Power y Chapman, 2015; Costa, Zepeda y Sirieix, 2014; Kamphuis, Jansen, Mackenbach y Van Lenthe, 2015; Oncini y Guetto, 2017; Paddock, 2016; Wills, Backett-Milburn, Roberts y Lawton, 2011), pero pocos se han realizado en países latinoamericanos (Morais et al., 2014; Morais, Gittelsohn, Fernandez, Roble y Baeza, 2016), por lo que este trabajo busca contribuir a esta área de conocimiento.

1 Este trabajo forma parte del proyecto de tesis doctoral de Arellano (2018). 
Premisas conceptuales

Aquí se retoma la propuesta teórica de Bourdieu sobre campo, habitus y capital, para analizar el sentido lógico de las prácticas de los agentes (Bourdieu y Wacqüant, 2005). El campo se comprende como el espacio del juego, una red de relaciones con reglas que definen las posiciones que ocupan los agentes, y con ello el acceso al poder y capitales que estructuran las relaciones de dominación-subordinación dentro del campo y en relación con otros campos (Bourdieu y Wacquiant, 2005). Se nace en el campo, es decir, en espacios jerarquizados donde se producen luchas continuas que redefinen su estructura en función de los capitales de los agentes y de la historia que la precede, interiorizada a través del habitus.

Para analizar un campo es necesario identificar el mapa de relaciones y las posiciones de los agentes que compiten por legitimarse. Los habitus de los agentes ubicados en posiciones socioeconómicas distintas permitirán examinar las posibilidades y oportunidades con las que cuentan en tal campo. Mediante este concepto se reconoce que los agentes no están determinados únicamente por causas externas o internas, sino que "los agentes sociales son el producto de la historia, de la historia del campo social en su conjunto y de la experiencia acumulada [...] son determinados solo en la medida en que se determinan a sí mismos" (Bourdieu y Wacqüant, 2005, p. 199).

Para analizar el campo alimentario y el sentido lógico de las prácticas que producen y reproducen un orden social a través de disposiciones a la acción, Bourdieu (2008) conceptualiza el habitus como principios generadores y organizadores de las prácticas, interiorizadas por medio de estructuras estructurantes (Bourdieu y Wacquiant, 2005). Es un concepto articulador entre las estructuras y la acción, que permite el análisis de estas disposiciones a la acción, construidas socialmente e incorporadas a través de esquemas de acción, apreciación y percepción de la vida cotidiana, mediante las cuales se generan las prácticas del sentido común, de lo razonable, esperado y deseado. Es el pasado que actúa en el presente y se corresponde con las condiciones de existencia, ubicando a los agentes sociales de clases y condicionamientos sociales distintos, es decir, en posiciones diferentes en los campos.

El análisis del poder es central y se expresa en relaciones de dominación y subordinación en las cuales tanto dominadores como subordinados han interiorizado, en sus habitus, posiciones diferenciadas, expresas en desigualdades sociales (Bourdieu, 2012; Bourdieu y Wacquiant, 2005). Los capitales posibilitan ciertas ventajas en relación con la posición que ocupa el agente en determinado campo y, con ello, el acceso a los capitales económicos, simbólicos, culturales, académicos y sociales. Bourdieu (2012) refiere que el consumo (incluso el alimenticio) es una encarnación de la clase social, ya que define el tipo de capitales a los que se tiene acceso y refleja la estratificación de los alimentos en relación con las clases sociales, como símbolos de distinción.

El mercado de la alimentación se compone del poder económico de la industria alimentaria, en la que trabajadores/as agrícolas, con su mano de obra, permiten a las agroempresas ofertar alimentos de primera calidad, pero ellos no son los consumidores finales, ya que se ubican en la posición más subordinada 
de este encadenamiento productivo. Son los agroempresarios quienes se disputan en el campo alimentario el poder para vender la mejor calidad y precio de producción, y así lograr una mejor posición y posibilidad de adquirir más capital económico y simbólico, que se representa por medio de certificaciones internacionales y un sitio renombrado en el mercado (Aranda y Castro, 2016).

La política social global sobre alimentación como parte del campo define acciones concretas para atender a poblaciones vulneradas como migrantes, mujeres, niñas/os, adultos mayores, pobres y trabajadores agrícolas. El campo alimentario contiene los agentes y poderes que entran en juego y definen las prácticas en determinados tiempos y espacios, de acuerdo con las posibilidades económicas, políticas, sociales y culturales. La práctica “está ligada al tiempo, no solamente porque se juega en el tiempo, sino también porque ella juega estratégicamente con el tiempo" (Bourdieu, 2008, p.131), de ahí que para el análisis relacional de las prácticas se les sitúe histórica y contextualmente. El uso del concepto de campo permite analizar procesos de diferenciación social, por medio del entramado de relaciones más próximas, para explicar las dinámicas sociales, conflictos, tensiones y ajustes que hacen los agentes en sus contextos específicos (Criado, 2008).

Miguel Alemán como zona de atracción para el trabajo agrícola

En 1950 se impulsó el distrito de riego por bombeo 051 Costa de Hermosillo, en donde se cultivaba algodón y trigo principalmente. Ahí se ubica Miguel Alemán, perteneciente al municipio de Hermosillo, Sonora, en el noroeste del país, entidad fronteriza con Estados Unidos. En sus inicios dicha población se conformó con población migrante de la región serrana y sur del estado (Moreno, 2006; Pérez, 2014) y después, con la tecnificación de la agricultura se requirió más mano de obra, y con ello comenzaron los ciclos de migración pendular de trabajadores, sobre todo provenientes del sur de México, quienes retornaban a sus lugares de origen al terminar el ciclo agrícola. Durante la década de 1990, al diversificarse los cultivos hortofrutícolas para exportación, se posibilitó que los migrantes se asentaran en las localidades aledañas a los campos para emplearse la mayor parte del año (Lara, 2010). Miguel Alemán es la localidad que más ha crecido con el asentamiento de población migrante (véase figura 1).

Miguel Alemán se ubica en el desierto sonorense, a $44 \mathrm{~km}$ de la línea costera y a 60 msnm. Registra uno de los índices más altos de irradiación solar en el mundo (Arancibia-Bulnes et al., 2014), su clima es muy seco y cálido; la temperatura promedio es de 25 a $28{ }^{\circ} \mathrm{C}$, pero en verano llega hasta $49{ }^{\circ} \mathrm{C}$ y desciende hasta $0{ }^{\circ} \mathrm{C}$ en invierno. Desde principios del año 2000 se reportó el aumento en la temperatura y las ondas de calor (Navarro et al., 2018), ocupó el segundo lugar nacional de muertes por golpes de calor de 2002 a 2010 (Calvario y Díaz, 2017). A esto se suma un alto riesgo por sequías, y aunque las lluvias son escasas generan un gran riesgo de inundaciones por la carencia de drenaje pluvial, como sucedió en septiembre de 2015. 


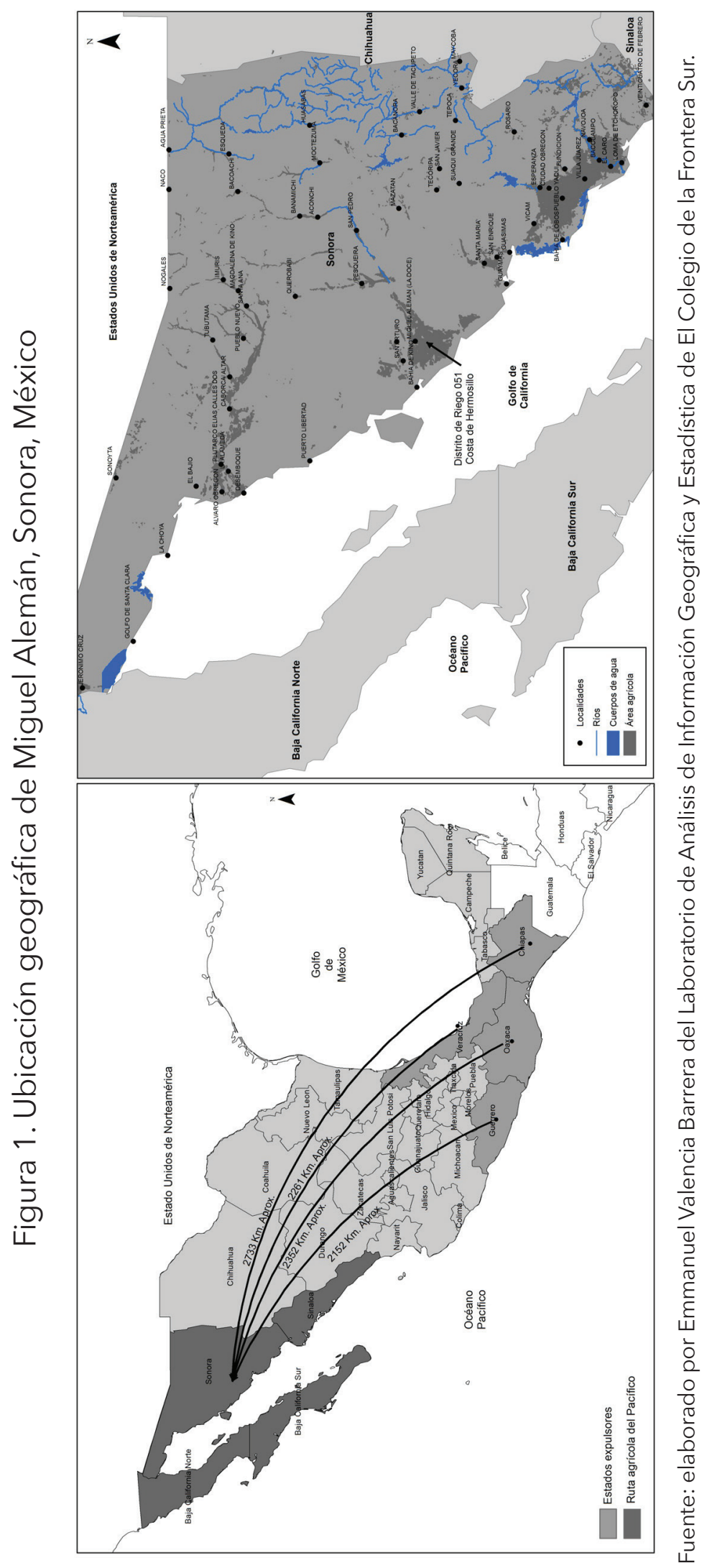


Los mantos acuíferos de la zona están sobreexplotados debido a las concesiones otorgadas a las agroempresas (Moreno, 2006), ya que 98\% de los pozos son privados. El uso extensivo de los recursos ha llevado a la salinización del agua (Reyes y Quintero, 2009; Salazar, Moreno y Lutz, 2012), la contaminación por agroquímicos y la deforestación de tierras (Instituto Municipal de Planeación [IMPLAN], 2016). En esta región operan más de 200 campos agrícolas altamente tecnificados, en una superficie de cosecha mayor a las 46 mil hectáreas de cultivos frutícolas, hortalizas y forrajes cuyo valor total de venta superó los 4.5 mil millones de pesos en el ciclo agrícola 2013-2014 (Comisión Nacional del Agua [CONAGUA], 2015). Estos productos se exportan a Europa, Estados Unidos, Canadá y China, y los que tienen el mayor valor de cosecha son la uva de mesa, la nuez y la naranja, seguidos por la calabaza, la sandía y el melón, mientras que el de los forrajes es considerablemente menor (CONAGUA, 2015; Villa y Bracamonte, 2013). La demanda internacional de uva de mesa ha llevado a que los productores tejan redes complejas de comercialización y certificación para exportarla (Lara y Sánchez, 2005).

En este contexto, miles de migrantes se han asentado en la zona al encontrar oferta de trabajo, según el IMPLAN, para 2016 la población era cercana a los 40000 habitantes, a la que se suma la flotante, que ha aumentado debido a la militarización de la frontera con Estados Unidos. La carencia de servicios como agua potable, drenaje, alumbrado, electricidad y pavimentación ubicó a Miguel Alemán como una de las zonas de atención prioritaria, debido al alto grado de marginación: más de $40 \%$ de la población de 15 años y más no tiene primaria completa y $12 \%$ es analfabeta (Secretaría de Desarrollo Social [SEDESOL], 2013), a pesar de que se localiza en uno de los estados con mayor índice de escolaridad y desarrollo social. Además, $28.9 \%$ de las viviendas habitadas tienen piso de tierra y 25.75 no cuenta con refrigerador (SEDESOL, 2013). En 2013 la localidad fue incluida en la Cruzada Nacional contra el Hambre, así como en otros programas federales, estatales y municipales de asistencia social en los cuales el apoyo alimentario es el eje central, debido a que parte de los habitantes vive en inseguridad y pobreza alimentaria (Castañeda, 2017; Centro de Derechos de la Montaña Tlachinollan, 2011), entre cuyos efectos en la salud están la obesidad, la desnutrición y la diabetes (Alcántara, 2014; Castañeda, 2017; Ortega y Alcalá, 2008; Ortega et al., 2012; Ramírez, 2002; Valdez, 2012). Estos elementos contextuales refieren la pertinencia de analizar la práctica alimentaria, y reconocer a los agentes, los capitales y las lógicas que configuran el campo alimentario en esta población en particular.

\section{Metodología}

A partir de un trabajo etnográfico se analizó información recabada de enero de 2016 a enero de 2018 en Miguel Alemán; se contó con la aprobación del comité de ética de El Colegio de la Frontera Sur para realizar el proyecto. El enfoque etnográfico permite describir y acercarse a la dinámica social y aprehender el sentido de las prácticas, para hilar marcos interpretativos sobre la realidad, 
entendida como un proceso desde el punto de vista del actor (Hammersley y Atkinson, 1994), para lo cual es necesario insertarse en el contexto donde trascurre la vida cotidiana de las personas, usar la observación, la entrevista, las notas de campo y los diarios analíticos (Denzin y Lincoln, 2005; Taylor y Bogdan, 1994). La primera técnica mencionada implica participar en el medio social, a través de pláticas informales, intercambio de puntos de vista, y tomar en cuenta la información no verbal de las prácticas de los agentes. Se realizaron entrevistas a profundidad y semiestructuradas a diversos informantes, observaciones en espacios distintos, revisión de informes gubernamentales y notas informativas en medios electrónicos, publicadas de 2016 a 2018. Toda esta información bibliográfica y empírica permitió analizar a los agentes, los poderes y las lógicas que operan en el campo alimentario.

Para las entrevistas se seleccionó a hombres y mujeres con experiencia de trabajo en los campos agrícolas y originarios de algún estado del sur y sureste de México, caracterizados por ser expulsores de población. Se incluyó a migrantes asentados y pendulares para mostrar la diversidad de dinámicas migratorias y sociales que se entretejen y construyen ciertas condiciones de posibilidad para alimentarse. Los asentados son los que tienen más de cuatro años de residir en un mismo lugar, mientras que los pendulares son los que se movilizan entre el lugar de origen y los sitios donde se emplean temporalmente (Chávez, 1999). Con el previo consentimiento informado, verbal y escrito, se realizaron 21 entrevistas: 11 a migrantes pendulares y 10 a asentados, se utilizaron pseudónimos para proteger su confidencialidad (véase tabla 1). Algunas entrevistas se audiograbaron con permiso previo, de otras se tomaron notas y todas fueron trascritas. Se realizó observación participante en hogares de migrantes asentadas, durante la elaboración de platillos, riego de plantas, almacenamiento de agua y acompañamiento al supermercado.

Las observaciones en espacios públicos se realizaron en supermercados y abarrotes, fondas, taquerías y comedores comunitarios. El primer punto incluyó seis comercios identificados por los/as participantes como lugares donde compran alimentos. Cuatro de ellos son abarrotes locales, uno regional y un supermercado trasnacional. Se acudió a los encargados de los establecimientos y se les informó el objetivo del estudio y se les preguntó sobre los alimentos de mayor venta. La guía de observación se centró en identificar qué se oferta, qué se compra y quiénes compran. Con el consentimiento de las encargadas, se realizó observación en dos fondas y taquerías, que incluyeron datos sobre la oferta de comida, los comensales y quiénes brindan el servicio (cocinar, servir, limpiar y cobrar). Se hizo observación en puestos ambulantes de comidas y bebidas ubicados sobre la avenida principal de la localidad.

En los tres comedores comunitarios se solicitó consentimiento al personal responsable para las observaciones e identificar quiénes acuden, qué tipo de alimentos se ofrecen, qué insumos tienen y quiénes los atienden. Además, se hicieron cuatro entrevistas semiestructuradas a dicho personal y a dos profesionales de la salud en centros adscritos a la Secretaría de Salud Pública. 
Tabla 1. Características sociodemográficas de los entrevistados

\begin{tabular}{|c|c|c|c|c|c|}
\hline $\begin{array}{c}\text { Tipo de } \\
\text { migración }\end{array}$ & Pseudónimo & Edad & $\begin{array}{c}\text { Lugar } \\
\text { de origen }\end{array}$ & Escolaridad & 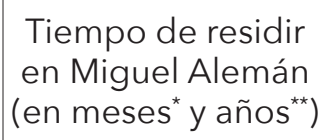 \\
\hline \multirow{10}{*}{$\begin{array}{l}\text { Migrantes } \\
\text { asentados }\end{array}$} & Jorge & 18 & Oaxaca & Secundaria inconclusa & $4^{\star *}$ \\
\hline & Mónica & 24 & Guerrero & Preparatoria inconclusa & $5^{* *}$ \\
\hline & Celia & 34 & Oaxaca & Secundaria & $14^{* *}$ \\
\hline & Elena & 40 & Chiapas & Ninguna & $7^{\star *}$ \\
\hline & Angelina & 50 & Chiapas & Ninguna & $12^{* *}$ \\
\hline & Arnoldo & 50 & Guerrero & Ninguna & $22^{* *}$ \\
\hline & Teresa & 50 & Guerrero & Ninguna & $22^{* *}$ \\
\hline & Isaura & 52 & Veracruz & Ninguna & $20^{\star \star}$ \\
\hline & Esperanza & 73 & Chiapas & Ninguna & $20^{* *}$ \\
\hline & Esteban & 74 & Chiapas & Ninguna & $20^{* *}$ \\
\hline \multirow{11}{*}{$\begin{array}{l}\text { Migrantes } \\
\text { pendulares }\end{array}$} & Juan & 18 & Chiapas & Preparatoria inconclusa & $5^{*}$ \\
\hline & Anselmo & 24 & Puebla & Primaria & $2^{\star *}$ \\
\hline & Lucía & 24 & Guerrero & ND & $3^{*}$ \\
\hline & Luz & 24 & Chiapas & Preparatoria inconclusa & $1^{*}$ \\
\hline & Germán & 25 & Chiapas & Primaria & $2^{* *}$ \\
\hline & José & 30 & Guerrero & ND & $3^{*}$ \\
\hline & Isidro & 30 & Guerrero & Ninguna & $3^{*}$ \\
\hline & Alma & 47 & Veracruz & Ninguna & $3^{* *}$ \\
\hline & Eduardo & 56 & Guerrero & Preparatoria inconclusa & $6^{*}$ \\
\hline & Sofía & ND & Veracruz & Ninguna & $9^{*}$ \\
\hline & Bernardo & ND & Veracruz & Ninguna & $9^{*}$ \\
\hline
\end{tabular}

ND: dato no disponible.

Fuente: Arellano, Alvarez, Eroza, Huicochea y Tuñón (2019).

Por último, la búsqueda de las notas en diarios locales en versión electrónica se centró en los conceptos Miguel Alemán, Costa de Hermosillo, alimentación, despensas, comida y apoyos; la selección del periodo: de 2016 a 2018 corresponde con el del trabajo de campo. ${ }^{2}$ Para la organización de los datos empíricos se utilizó el programa NVivo, versión 10.

2 El acceso a la base de datos de periódicos nacionales, estatales y locales sobre población jornalera en México fue posible gracias a Patricia Aranda y Yolanda Velázquez, del Centro de Estudios en Salud y Sociedad de El Colegio de Sonora, responsables del proyecto "Migración interna y salud de la población jornalera. Análisis de prensa y textos académicos sobre trabajo agrícola en la región Noroeste 2013-2018". 


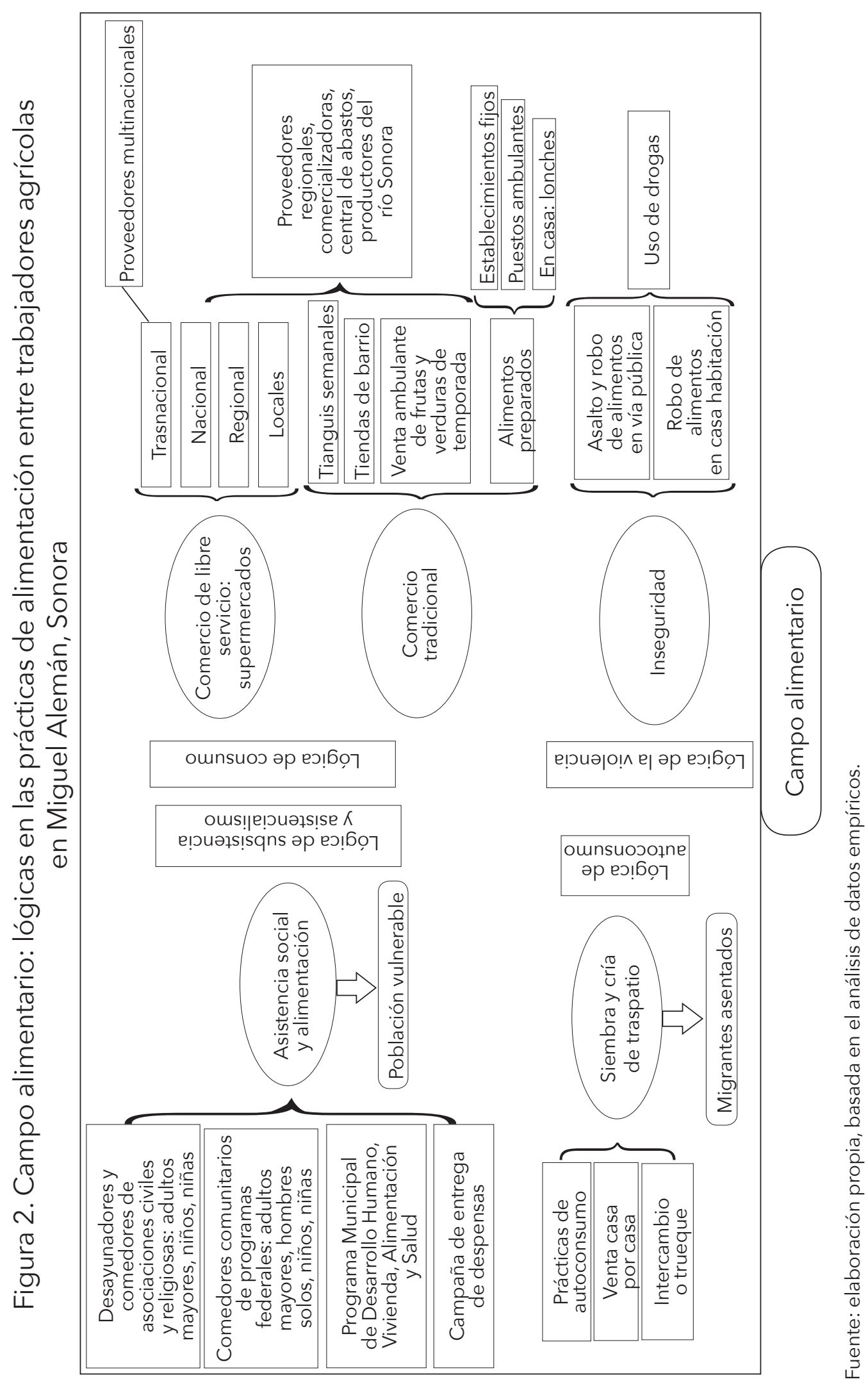


El campo alimentario: lógicas diversas de una práctica necesaria

En el campo alimentario confluyen diversos poderes que, desde una escala global, definen la política alimentaria, entre éstos el poder económico de la industria alimentaria que, a través de procesos de mercantilización, define qué tipo de alimentos llegan a las poblaciones según la posición que ocupan en los campos sociales.

Con base en los resultados empíricos se presentan cuatro ejes de análisis, para identificar las lógicas y agentes que intervienen en la conformación del campo alimentario en Miguel Alemán: a) el mercado de la alimentación, centrado en la lógica de consumo; b) la lógica asistencialista, que opera en los programas sociales; c) las prácticas de autoconsumo; d) el impacto de la violencia social y su relación con las posibilidades de acceder a alimentos, en un contexto de inseguridad generalizada.

Cada una de estas lógicas se relaciona con procesos estructurales y socioculturales, como las políticas de la industria alimentaria, las redes de comercialización, las economías globalizadas en contraste con la economía doméstica y local, la del trabajo agrícola, así como los procesos de exclusión social, para los cuales se diseñan programas gubernamentales y civiles, que a nivel microsocial posibilitan ciertas prácticas de alimentación entre los agentes situados contextual e históricamente. El análisis relacional de los cuatro ejes temáticos permite comprender el sentido lógico de las prácticas de alimentación entre trabajadores agrícolas en el cual se relacionan diversos procesos (véase figura 2).

La lógica de consumo:

el mercado de la alimentación en un contexto migratorio

Hay varios agentes y poderes que posibilitan el acceso a alimentos basados en la lógica de consumo, como el Programa de Desarrollo Urbano del Centro de Población de Miguel Alemán 2016, que reporta la existencia de 167 unidades que ofrecen alojamiento temporal y preparación de alimentos y bebidas, así como otras 118 dedicadas a la industria alimentaria a pequeña escala, con uno a cinco empleados por unidad (IMPLAN, 2016).

En los 4.6 kilómetros de longitud de la avenida principal de Miguel Alemán, que es parte de la carretera a Bahía de Kino, lugar turístico, se encuentran los siguientes comercios expendedores de alimentos: seis tiendas de autoservicio regionales y una trasnacional, dos de conveniencia, 11 restaurantes, 20 puestos ambulantes de comida, nueve establecimientos de comida para llevar, siete refresquerías y una pastelería regional, a lo que se suma la venta ambulante de frutas de temporada (naranja, sandía, mandarina, melón); al menos cada 80 metros hay un sitio para comprar alimentos (información obtenida en el trabajo de campo, enero de 2018). Pero esta situación cambia en las tiendas de barrio, ubicadas dentro de los hogares, que no ofertan variedad de productos frescos. En la tabla 2 se enlistan los alimentos de mayor demanda en los seis 
establecimientos visitados, donde la venta de los no perecederos es mayor en comparación con la de frutas y verduras.

Tabla 2. Reporte de ventas de alimentos por tipo de establecimiento en Miguel Alemán

\begin{tabular}{|c|c|c|c|}
\hline $\begin{array}{c}\text { Tipo de } \\
\text { establecimiento }\end{array}$ & No perecederos & Perecederos & $\begin{array}{c}\text { Carnes } \\
\text { y embutidos }\end{array}$ \\
\hline \multirow{5}{*}{ Trasnacional } & Jugos tetrabrik & Papa & Pollo entero, muslo americano \\
\hline & Sopa instantánea & Plátano & Carne molida \\
\hline & Coca Cola & Tomate & Alitas de pollo \\
\hline & Atún & Manzana & Queso chihuahua \\
\hline & Agua & & Jamón y salchicha económica \\
\hline \multirow{5}{*}{ Regional } & Arroz & Tomate & \\
\hline & Frijol & Cebolla & \\
\hline & Sopa & Chile & \\
\hline & Azúcar & Papa & \\
\hline & Maseca & Cilantro & \\
\hline \multirow{5}{*}{ Local } & Huevo & Papa & Pollo \\
\hline & Frijol & Tomate & Carne de puerco \\
\hline & Azúcar & Cebolla & Hueso de res y puerco \\
\hline & Aceite & Chiles & \\
\hline & Manteca & & \\
\hline \multirow{5}{*}{ Local } & Frijol pinto & Tomate & Pollo \\
\hline & Sopas & Chile & Salchicha de pavo económica \\
\hline & Harina de trigo & Cebolla & \\
\hline & Aceite & Papa & \\
\hline & Arroz & Plátano & \\
\hline \multirow{3}{*}{ Local } & Frijol & Frutas y verduras & \\
\hline & Huevo & Plátano macho & \\
\hline & & Hoja de plátano & \\
\hline \multirow{3}{*}{ Local } & Harina de trigo & Papa & Chorizo casero \\
\hline & Huevo & Tomate & Chilorio casero \\
\hline & Frijoles caseros & Cebolla & \\
\hline
\end{tabular}

Fuente: elaboración propia, basada en información empírica. 
De acuerdo con los testimonios, es más económico comprar alimentos en los supermercados que en las tiendas de barrio, en donde lo que más se vende son refrescos embotellados y alimentos procesados, como galletas y papas fritas: "Ahí en la tienda $M$, hay de todo, ofertas los fines de semana, porque en los changarros que no son tan conocidos, está bien caro" (Esperanza, de Chiapas). Esto se relaciona con la red de comercialización, ya que los changarros ${ }^{3}$ compran a comercializadoras o bodegas de autoservicio de la localidad, y aumentan los precios. El supermercado trasnacional se instaló hace siete años, y es uno de los proveedores principales de los changarros de Miguel Alemán y de las tiendas de los campos agrícolas. El encargado de este comercio reportó que los productos de mayor venta son los jugos, refrescos y polvos para preparar bebidas, sobre todo en la temporada en que el trabajo es intenso y las temperaturas son altas. También dijo que como los precios de frutas y verduras los establece la administración central, los supermercados locales los ofertan más baratos, al comprar a pequeños y medianos productores regionales, sobre todo del río Sonora, a cuya cadena de comercialización directa se suman los locatarios de la central de abastos de Hermosillo.

Sin embargo, la variedad de alimentos es reducida: tomate, cebolla, chile, zanahoria, calabaza, cilantro y papa. Las condiciones climáticas de la región permiten el cultivo de alimentos que resultan culturalmente apropiados para los sonorenses, que se ofertan en el mercado local. Los habitus alimentarios de la población migrante se corresponden con productos de zonas templadas del sur y sureste mexicano y, si bien no se puede generalizar, entre los alimentos esenciales de la dieta mesoamericana que se consume en tales estados están maíz, frijol, calabaza y chile, cultivados en la milpa, junto con quelites y otras verduras propias de cada región, lo que da lugar a una variedad culinaria compleja (Carrillo, 2009; Vargas, 2002). Dichos alimentos no están disponibles geográfica ni económicamente, por lo que "aquí casi no comemos verduras" (Elena, de Chiapas), pues los migrantes están asentados en un desierto, que se significa, además, como un desierto alimentario (Joassart, Rossiter y Bosco, 2017), que más allá de la disponibilidad se relaciona con la desigualdad social. Las dificultades para acceder a alimentos frescos se recrudece por la precariedad económica, contradicción manifiesta, al ser un lugar donde se producen variedades de frutas y hortalizas, pero que se comercializan entre un grupo poblacional con capacidad adquisitiva. Los/as trabajadores/as agrícolas ven restringida la posibilidad de decidir y acceder a estos alimentos, al ubicarse en una posición subordinada y precaria en este campo social, reflejo de las múltiples desigualdades.

En ciertas temporadas, en la vía pública se venden productos de la "rezaga" de lo que cultivan y cosechan en los campos donde trabajan pero que no cumplen con todos los requisitos para la exportación, expresión de los procesos de distinción entre agentes que pueden comer alimentos de primera calidad y otros que no cuentan con los capitales económicos ni simbólicos para acceder a éstos. Algunos como naranja, mandarina, sandía, melón, uva y nuez se comercializan por temporadas, los venden en la calle los llamados "verduleros", quienes anuncian sus productos por un altavoz. Otros más se ubican en puntos estratégicos de

3 Comercios pequeños dentro de los hogares. 
la comunidad y esperan a los clientes. Los fines de semana se instala un tianguis, que se extiende por cinco calles, en dos lugares venden frutas y verduras, traídas de la central de abastos de Hermosillo, que se ofertan en bolsas plásticas por 10 pesos (tomate, cebolla y chile). Aunque se gestionó la operación de un mercado ante autoridades municipales, no se ha concertado el permiso para instalarlo.

En las observaciones en tres supermercados locales, referidos por los participantes y que ofertan "productos del sur”, se encontró que los propietarios son originarios de Oaxaca, con lo que se crea un vínculo identitario; solo en uno de ellos se venden alimentos producidos en el sur y sureste mexicano: plátano macho y dominico, maíz morado, chile pasilla, ancho y habanero, mamey, chicharrón prensado de puerco y hoja de plátano para tamales. Este negocio abrió recientemente una sucursal, y se anuncia en la radio comercial de Hermosillo. Personal encargado relató que hace 15 años iniciaron con una tienda pequeña en el hogar, y creció al posicionarse en el gusto de la población. Algunos de sus productos son de Puebla, los cuales adquieren a través de una comercializadora de Hermosillo. Sin embargo, en 2017 ésta cerró, por lo que han reducido la oferta de productos "del sur".

Durante los fines de semana dos de los tres establecimientos ofrecen trasporte gratuito hacia algunos campos agrícolas. Esta opción es una oportunidad de ahorrar y contribuye con su capital simbólico. Los datos empíricos muestran que al migrar de localidades en transición de economías de autoconsumo a otra de consumo, esta lógica domina la práctica alimentaria, ya que: “Aquí uno trabaja y todo lo que quiere comer, lo tienes que comprar y ahí se va todo. Si no trabajas, no comes" (Mónica, de Guerrero), expresión de la mercantilización de la vida cotidiana (Pla, 2017). Gran parte de lo que se gana con el trabajo agrícola se invierte en alimentación, y en ocasiones este ingreso es insuficiente, de ahí que una parte de la población recurra a programas sociales o prácticas de autoconsumo, como estrategia frente a la pobreza alimentaria.

\section{La lógica del asistencialismo: programas sociales}

de atención a población vulnerable

A partir del encadenamiento de políticas sociales nacionales y mundiales, se reconocen los agentes de poder que configuran el campo alimentario y las acciones de los Estados. Una política global como los Objetivos del Milenio, a través del objetivo Hambre cero, repercutió en la política mexicana y se tradujo en el Sistema Nacional contra el Hambre y la Cruzada Nacional contra el Hambre, lanzada en enero de 2013 (SEDESOL, 2016). En ésta se incluyó a Miguel Alemán, como zona de atención prioritaria debido a su rezago social, a pesar de ubicarse en un estado con puntuaciones bajas en tal índice, lo que indica las desigualdades al interior. En Sonora, 21\% de la población total está en carencia alimentaria, mientras que dicho porcentaje nacional es de 20; es el único indicador que supera la media nacional (SEDESOL, 2018). En las notas informativas se alude a la pobreza extrema y las actividades gubernamentales y civiles para la entrega de canastas alimenticias, como se muestra en la tabla 3. 
Tabla 3. Notas informativas en medios electrónicos, 2016-2018

\begin{tabular}{|c|c|c|}
\hline Año & Encabezado & Disponible en \\
\hline \multirow{3}{*}{2018} & $\begin{array}{l}\text { Crece Miguel Alemán en } \\
\text { población y problemas }\end{array}$ & $\begin{array}{c}\text { http://www.elimparcial.com/EdicionEnLinea/Notas/ } \\
\text { noticias/08052017/1211875-crece-miguel-ale- } \\
\text { man-en-poblacion-y-problemas.html }\end{array}$ \\
\hline & $\begin{array}{l}\text { Arranque de obra de } \\
\text { comedor comunitario } \\
\text { en Miguel Alemán }\end{array}$ & $\begin{array}{c}\text { http://www.expreso.com.mx/seccion/hermosi- } \\
\text { Ilo/30718-arranque-de-obra-de-comedor- } \\
\text { comunitario-en-miguel-aleman.html }\end{array}$ \\
\hline & $\begin{array}{l}\text { Llevan atención médica } \\
\text { a Miguel Alemán }\end{array}$ & $\begin{array}{c}\text { http://www.entornoinformativo.com.mx/2018/03/18/ } \\
\text { Ilevan-atencion-medica-al-miguel-aleman/ }\end{array}$ \\
\hline \multirow{7}{*}{2017} & $\begin{array}{l}\text { Proyecto de albergue en } \\
\text { Miguel Alemán no está } \\
\text { concluido: gobernadora }\end{array}$ & $\begin{array}{l}\text { http://www.uniradionoticias.com/noticias/hermosil- } \\
\text { lo/503553/proyecto-de-albergue-en-miguel-ale- } \\
\text { man-no-esta-concluido-gobernadora.html }\end{array}$ \\
\hline & $\begin{array}{l}\text { ISSSTESON entrega } \\
\text { apoyos a poblado } \\
\text { Miguel Alemán } \\
\text { Albergue proyectado en } \\
\text { Miguel Alemán lleva un } \\
\text { 60\% de avance: DIF }\end{array}$ & $\begin{array}{c}\text { http://marquesinapolitica.com/105763/ } \\
\text { http://www.uniradionoticias.com/noticias/hermosil- } \\
\text { lo/498223/albergue-proyectado-en-miguel-aleman- } \\
\text { lleva-un-60-de-avance-dif.html }\end{array}$ \\
\hline & $\begin{array}{l}\text { Entrega DIF Sonora } \\
\text { apoyos a pobladores de } \\
\text { la Costa de Hermosillo } \\
\end{array}$ & $\begin{array}{l}\text { http://elportaldelagente.mx/entrega-dif-sonora-apoy- } \\
\text { os-a-pobladores-de-la-costa-de-hermosillo/ }\end{array}$ \\
\hline & $\begin{array}{l}\text { Sonora gasta } 30 \text { mdp } \\
\text { en concierto de Plácido } \\
\text { Domingo, pero lo } \\
\text { recaudado no alcanza } \\
\text { para construir albergue }\end{array}$ & $\begin{array}{l}\text { https://www.animalpolitico.com/2017/11/placido-do- } \\
\text { mingo-albergue/ }\end{array}$ \\
\hline & $\begin{array}{l}\text { En poblado Miguel } \\
\text { Alemán niños comen } \\
\text { una vez al día gracias a } \\
\text { la iniciativa privada }\end{array}$ & $\begin{array}{c}\text { https://proyectopuente.com.mx/2017/12/07/en-po- } \\
\text { blado-miguel-aleman-ninos-comen-una-vez-al-dia- } \\
\text { gracias-a-la-iniciativa-privada/ }\end{array}$ \\
\hline & $\begin{array}{l}\text { Detienen a hombre por } \\
\text { robo de fruta en } \\
\text { poblado Miguel Alemán }\end{array}$ & $\begin{array}{l}\text { http://www.elimparcial.com/EdicionEnLinea/Notas/ } \\
\text { Policiaca/20112017/1279312-Detienen-a-hombre- } \\
\text { por-robo-de-fruta-en-Poblado-Miguel-Aleman.html }\end{array}$ \\
\hline & $\begin{array}{c}\text { Hurtan naranjas } \\
\text { en la Costa } \\
\text { Entregan apoyos } \\
\text { a familias de } \\
\text { Miguel Alemán } \\
\text { Buscan abatir rezagos } \\
\text { en Miguel Alemán } \\
\text { Llevan jornada } \\
\text { comunitaria al } \\
\text { Miguel Alemán } \\
\text { Entregan becas a } \\
\text { personas con } \\
\text { discapacidad en el } \\
\text { poblado Miguel Alemán }\end{array}$ & $\begin{array}{l}\text { https://www.elsoldehermosillo.com.mx/hermosillo/ } \\
\text { construiran-guarderia-en-la-costa } \\
\text { http://www.entornoinformativo.com.mx/2017/09/03/ } \\
\text { entregan-apoyos-a-familias-de-miguel-aleman/ } \\
\text { http://www.entornoinformativo.com.mx/2017/03/30/ } \\
\text { buscan-abatir-rezagos-en-miguel-aleman/ } \\
\text { http://www.entornoinformativo.com.mx/2017/02/28/ } \\
\text { Ilevan-jornada-comunitaria-al-miguel-aleman/ } \\
\text { http://www.entornoinformativo.com.mx/2017/02/01/ } \\
\text { entregan-becas-a-personas-con-discapaci- } \\
\text { dad-en-el-poblado-miguel-aleman/ }\end{array}$ \\
\hline
\end{tabular}




\begin{tabular}{|c|c|c|}
\hline \multirow[b]{3}{*}{2016} & $\begin{array}{l}\text { Abren tienda Diconsa } \\
\text { en el Miguel Alemán } \\
\text { Apoyan a familia del } \\
\text { poblado Miguel Alemán }\end{array}$ & $\begin{array}{l}\text { http://www.entornoinformativo.com.mx/2016/08/25/ } \\
\text { abren-tienda-diconsa-en-el-miguel-aleman/ } \\
\text { http://www.entornoinformativo.com.mx/2016/05/18/ } \\
\text { apoyan-a-familia-del-poblado-miguel-aleman/ }\end{array}$ \\
\hline & $\begin{array}{l}\text { Se encuentra comisaría } \\
\text { Miguel Alemán dentro } \\
\text { de las más pobres }\end{array}$ & $\begin{array}{l}\text { http://www.elimparcial.com/EdicionEnLinea/Notas/ } \\
\text { noticias/12082016/1114582-se-encuentra-comisaria- } \\
\text { miguel-aleman-dentro-de-las-zonas-mas-pobres.html }\end{array}$ \\
\hline & $\begin{array}{c}\text { Miguel Alemán con } \\
\text { mayor índice de } \\
\text { pobreza extrema } \\
\text { Construirán guardería } \\
\text { en la Costa } \\
\text { Detienen a joven por } \\
\text { robar nueces en Miguel } \\
\text { Alemán }\end{array}$ & $\begin{array}{c}\text { https://www.elsoldehermosillo.com.mx/hermosillo/ } \\
\text { poblado-miguel-aleman-con-mayor-indice-de-pobre- } \\
\text { za-extrema } \\
\text { https://www.elsoldehermosillo.com.mx/hermosillo/ } \\
\text { construiran-guarderia-en-la-costa } \\
\text { http://www.entornoinformativo.com.mx/2016/11/21/ } \\
\text { detienen-a-joven-por-robar-nueces-en-miguel-ale- } \\
\text { man/ }\end{array}$ \\
\hline
\end{tabular}

Fuente: elaboración propia, basada en notas periodísticas sobre Miguel Alemán, publicadas de enero de 2016 a mayo de 2018.

El programa Sin Hambre se puso en marcha en diciembre de 2016, con un comedor comunitario, en un centro dirigido por el gobierno municipal. En julio de 2017 se abrió otro comedor, aunque era operado por personas de la sociedad civil desde hacía siete años. En las observaciones y entrevistas realizadas en ambos lugares se advirtió que el programa no incluye frutas, verduras ni carnes en su canasta básica, lo que se contrapone con los objetivos de lograr la seguridad alimentaria sana y variada. El programa define una cuota de recuperación para la compra de perecederos, pero el personal de ambos comedores reiteró que no es posible aplicarla debido a las precarias condiciones económicas de la población, y que cuando establecieron esta cuota los beneficiarios dejaron de asistir, principalmente niños y niñas.

Los encargados del comedor operado por la sociedad civil refieren que la canasta alimentaria brindada por el gobierno cubre entre 60 y $70 \%$ de las necesidades alimenticias de la población atendida, y que en el programa no se debe atender a más de 120 personas diarias aunque, en ciertas temporadas, llegan hasta 200 niños/as y adultos mayores. Este comedor construye estrategias de búsqueda de donaciones en especie o en efectivo, para ofrecer menús variados con alimentos frescos de origen vegetal y animal.

Otro de los comedores que forma parte del campo alimentario en Miguel Alemán es administrado por un patronato de agricultores desde 1990, y otorga comidas calientes a adultos mayores y niños/as. Este servicio empezó en una congregación religiosa a la que se sumó el patronato, que consigue las donaciones y compra los alimentos. En 2017 ofreció más de 50000 platillos calientes, y en entrevista con personal encargado y en observación se registró la preparación de platillos con carnes rojas, verduras, frijol y tortilla de maíz. 
Los tres comedores reciben arroz, frijol, aceite, azúcar, soya, agua embotellada y sopas de pasta, como los suministros más comunes, y en ocasiones también carne deshidratada con verduras, frutas en almíbar y barras de fruta con chile forman parte de la canasta, como estrategia para cubrir el consumo de proteína animal y frutas, aunque están procesados industrialmente. Estos datos indican la pertinencia de evaluar la calidad nutricional de los alimentos ofrecidos en los programas sociales.

Otro elemento común observado en los tres comedores fue que la fuerza de trabajo y el saber de las mujeres es un capital necesario para su funcionamiento. Si bien en ambos atendidos por la sociedad civil algunas mujeres reciben un salario (dos en uno y cuatro en otro), en los tres participan voluntariamente mujeres en diversas tareas. Son parte del capital humano que requiere la estructura de la política y acción social, aunque su trabajo no cuente con reconocimiento simbólico ni económico. Los hombres adultos mayores reproducen su posición como receptores de los cuidados a través de la alimentación, al ser los usuarios principales del servicio. Esto se vincula con las construcciones socioculturales de género contenidas en políticas y prácticas concretas que reproducen las desigualdades. En los comedores de la sociedad civil no se recibe a jóvenes ni a personas en edad productiva, porque pueden "ver un trabajito" (encargado de comedor, Miguel Alemán), con el cual obtener ingresos para comer, en cambio en el gubernamental se recibe a personas de cualquier edad y sexo. Así, los habitus se reproducen y se incorporan en las estructuras objetivas y esquemas mentales, que ubica a los agentes en posiciones de poder distintas, en este caso, las mujeres como cuidadoras y los hombres como sujetos de cuidados.

La lógica del autoconsumo:

agricultura y cría de traspatio en población asentada

La siembra de traspatio y la cría de animales para el autoconsumo o venta en pequeño fue la estrategia registrada ante la lógica de consumo, en cuatro grupos domésticos asentados hace más de 10 años. Las mujeres utilizan el saber de la agricultura como parte de su capital, para cultivar en sus patios algunos "aromas" como hierba santa, chipilín y otras especias para condimentar comidas, como parte de su capital material y simbólico.

A través de los circuitos migratorios se comparten saberes y prácticas relacionadas con los ajustes en la alimentación en el lugar de asentamiento; las semillas forman parte del equipaje: "Mi hijo trajo semilla de chilacayote [...] Chile traíamos matitas y ahora se llenó" (Esperanza, de Chiapas).

La reproducción de estas prácticas permite conservar los habitus alimentarios, expresión de identidad y prácticas sustentables de alimentación. Si bien no es algo generalizado, el capital simbólico de la alimentación se traduce en el reconocimiento de los agentes que cultivan y venden en pequeña escala productos como plátano macho, nopal y maíz, así como animales de traspatio, además de contribuir a la economía doméstica, como relató Angelina, de Chia- 
pas: "Le dije a mi nuera, -antes de irte, vende aunque sea en $\$ 50$ cada pato, algo son $\$ 100$

Estas prácticas se conciben como estrategias de ahorro frente al sistema que impone el consumo como forma de adquirir los alimentos, también para mejorar la economía doméstica: "Sembramos chile, sembramos cilantro, unos quelites, pa' no comprarlos [...] [en] la pobreza se busca por dónde” (Arnoldo, de Guerrero).

En las observaciones de los grupos domésticos se registró el intercambio de algunas especias, semillas, plantas y pollos, como parte de sus activos y una forma de reproducir relaciones tradicionales y construir lazos de cohesión social, sobre todo entre quienes son del mismo lugar. Estas prácticas pueden analizarse como estrategias de los agentes frente a la posición subordinada que guardan en el campo, ya que los ingresos económicos resultan insuficientes para adquirir lo necesario. También se observó la venta de casa en casa de productos derivados del cultivo de traspatio como nopales, cebollín, limón y hoja de plátano. Las mujeres asentadas han incursionado en la venta de tortillas de harina de trigo, como actividad económica, por lo que es común observar letreros que ofertan este producto en el exterior de las casas; todas estas estrategias de economía doméstica femenina se relacionan con las construcciones de género que las posicionan como cuidadoras principales de la alimentación (Brunet y Santamaría, 2016; Criado, 2004; Kleider, 2015), al tiempo que este saber les permite generar un ingreso: "Cuando hacía tortilla de harina, tenía muchísimo abonado" (Isaura, de Veracruz).

Los agentes, a pesar de su posición subordinada en el campo, ponen en marcha sus capitales y estrategias para afrontar la precariedad realizando actividades para la generación de ingresos más allá del trabajo agrícola. Las mujeres contribuyen y en ciertos momentos son las únicas que aportan a la economía doméstica, al ofertar alimentos preparados a los "abonados", hombres solos que contratan este servicio y pagan semanalmente, así como en la venta al por menor de las plantaciones y/o animales de traspatio.

La lógica de la violencia:

su repercusión en las prácticas de alimentación

La violencia emergió como un tema que condiciona la práctica alimentaria y se relaciona con la exclusión y marginación social que impera en la localidad, traducida en inseguridad cotidiana. El común denominador de las notas policiacas en los medios locales son los robos y asaltos de los "macheteros", hombres que cometen atracos con cuchillos o picos, así como decomisos de droga. En 2017 el Ejército se instaló por casi seis meses en oficinas gubernamentales como medida ante la inseguridad, y a tres meses de su retirada, en abril de 2018, asesinaron a un policía municipal dentro del centro comunitario frente a cientos de personas, cuando intentaba frenar el robo de apoyos gubernamentales. 
Los informantes refieren el robo de alimentos en los hogares y en la vía pública, debido a la carencia de dichos bienes. Los trabajadores agrícolas dicen que los asaltan para robarles lonches que llevan al campo, por lo que transitar durante las madrugadas a los puntos de llegada de las camionetas, que los trasportan a los campos agrícolas, se convierte en un riesgo sobre todo para los varones: "Aquí es muy feo [...] la delincuencia es costumbre, se vive la pobreza, ya nomás falta que medio mundo ande pidiendo para comer, porque hasta la comida se la andan robando, te asaltan para quitarte el lonche" (Eduardo, de Guerrero).

También se reporta el robo en casa habitación, incluso el de alimentos por integrantes del grupo doméstico, quienes después los ofertan para obtener dinero y comprar drogas, como relató Esperanza, de Chiapas: “Allá [habitación de su nuera] tengo el frijol, la masa, huevo, tengo todo, porque él [su pareja] lo cambia o lo vende y trae alcohol". Frente a esto, su estrategia para cuidar los alimentos es esconderlos.

También se roban los enseres y utensilios necesarios para la preparación de alimentos, para venderlos en el mercado ilegal: "El otro día me robaron el tanque de gas y la parrilla que tenía ahí afuera, en el día, salí a la tienda y cuando regresé se la habían llevado. Por eso siempre estoy encerrada" (Elena, de Chiapas). De ahí que los agentes limiten el libre tránsito en la comunidad, como medida de protección.

Esperanza comentó que también los animales de traspatio son objeto de robo: "Tenía yo [gallinas], pero se las robaron los chamacos". Esta situación de riesgo refleja lo complicado de las relaciones sociales en la comunidad, donde los atracos y la impunidad son la constante, traducida en estrategias de autocuidado como dejar de acudir a los establecimientos a ciertas horas debido al riesgo: "A veces tienen mucha inseguridad alimentaria porque nomás para allá es una tiendita y bastante peligroso en la noche, ya nos ha tocado que andan con machetes" (Ana, personal de salud). La inseguridad alimentaria se significa no solo en el acceso y disponibilidad de alimentos, sino en las posibilidades de libre tránsito y salvaguardar la seguridad física, lo que muestra el entramado de relaciones que cruzan la práctica alimentaria.

El motivo principal de los atracos es robar para comprar droga, lo que complejiza la problemática de inseguridad y adicciones, ya que "aquí se viene a aprender a ser drogadicto. Pero es mala, no comes, se endalgadece [perder peso corporal], robas [...] y la verdad, gastarlo en drogas, pues mejor la comida" (Anselmo, de Puebla). El uso de drogas impacta en los recursos económicos destinados para la compra de alimentos y, por lo tanto, en la organización doméstica para cubrir esta necesidad, como relató Angelina, de Chiapas: "Anda mal, no trae ni un peso, ya no le di lonche en la mañana, ni modo es mi hijo, pero no". Esto afecta las relaciones sociales en los grupos domésticos, y genera conflictos y desacuerdos vinculados con la precariedad económica que limita las posibilidades de alimentarse.

La dinámica social de Miguel Alemán se vincula con procesos estructurales de desigualdad y exclusión de las personas, por ser migrantes pobres y cuya mano de obra se considera desechable y sin derechos (Valdivia y Sánchez, 2017) y así, por medio de la violencia cotidiana se reproduce su posición subordinada en un campo vital como el alimentario. 


\section{Conclusiones}

Son múltiples los procesos estructurales que configuran el campo alimentario global, y en este trabajo se mostró cómo algunos de sus elementos se relacionan entre sí en un contexto sociohistórico particular, a partir de lógicas, poderes y capitales que entran en juego para estructurar el habitus alimentario entre jornaleras/os que viven en una comunidad caracterizada por la movilidad humana y el trabajo agrícola extensivo. El análisis relacional, desde el enfoque teórico de Bourdieu, permite reflexionar sobre las lógicas, agentes y poderes que operan en el campo, produciendo y reproduciendo las relaciones de poder que trastocan la práctica alimentaria.

Los datos empíricos muestran la diversidad de agentes y capitales que configuran el campo alimentario, evidenciando la confluencia de prácticas basadas en la lógica del consumo, así como las estrategias que los trabajadores agrícolas ponen en práctica. La lógica del consumo estructura procesos de diferenciación de clase, y ubica a los agentes, en este caso a los trabajadores agrícolas, en relaciones subordinadas en campos distintos. Las condiciones históricas en las localidades de origen, de tránsito y asentamiento se combinan para reproducir una posición subordinada en los habitus de este sector productivo. Ubicarse en la escala más baja de la producción agroindustrial se materializa en relaciones laborales flexibles, y con ello en dificultades para el acceso al capital económico necesario para insertarse en las sociedades de consumo. Si bien los trabajadores agrícolas no son pasivos y crean estrategias, como el autoconsumo y el intercambio de semillas, plantas y alimentos entre las redes cercanas, las condiciones de movilidad constante dificultan la puesta en práctica de estas estrategias, sobre todo para los hombres migrantes pendulares, de aquí que sean ellos los usuarios principales de los servicios de comedores comunitarios, mientras que las mujeres continúan realizando estos trabajos. Estas normativas de género se relacionan con los habitus que reproducen las desigualdades, que definen la tarea alimentaria como femenina.

Aquí se reconoce la capacidad de los agentes cuyas condiciones de vida precarias circunscriben su práctica alimentaria a lo económicamente accesible, lo que obtienen a partir de la mercantilización de su mano de obra. Si bien reconocen que los alimentos frescos y naturales son saludables, pero al no poseer el capital económico necesario, su acceso se limita a lo posible, es decir, a lo más barato y de menor calidad, lo que resulta paradójico al ser ellos y ellas quienes cosechan los de primera calidad, pero que no consumen, así se refleja la desigualdad en el acceso a los alimentos. De ahí que sea importante reconocer las estrategias que ponen en práctica para hacer frente al modelo económico que los subordina, mientras resisten la violencia estructural y social que impacta sus condiciones de existencia, incluso la alimentación.

Otra parte de la población es aún más vulnerada, hasta el punto de encontrar en los comedores comunitarios la posibilidad de alimentarse. Esta situación muestra la precariedad y exclusión social que sufren todos los grupos de edad, ya que los niños y los adultos mayores son sujetos de programas de asistencia social alimentaria, expresión de una pobreza continua y sostenida en su cur- 
so de vida; una especie de trayectoria de subordinación caracterizada por la inseguridad y la incertidumbre. Hombres adultos mayores, quienes trabajaron por muchos años en los campos agrícolas y que están enfermos y sin hogar, se alimentan a diario en los comedores comunitarios. Durante sus años como jornaleros vivieron reiteradas violaciones laborales, mismas que continúan invisibles, social y legalmente, exponiéndolos hasta la pobreza alimentaria y la situación de calle como se observó en la localidad. Asimismo, las condiciones materiales de vida se recrudecen debido a la inseguridad cotidiana y normalizada en perjuicio de la alimentación, tanto por restringir el libre tránsito, como sufrir asaltos ya que los alimentos son bienes valorados y necesarios, pero escasos para parte de la población, por lo que son motivo de sustracción violenta en los hogares y en la vía pública.

Por otro lado, la presencia de comercios relacionados con la pertenencia étnica configura el campo alimentario en el cual entran en juego las compañías trasnacionales, mientras se entrecruzan con redes cortas de comercialización, la venta ambulante (como los verduleros y los tianguis) e incluso la de casa en casa de productos de traspatio. Estas prácticas, centradas en la economía doméstica, se significan como estrategias frente al modelo comercial de consumo y la posibilidad de generar recursos propios, a la vez que permite la reproducción identitaria. Además, reflejan la capacidad de construir estrategias de sobrevivencia ante la precariedad. En última instancia, expresa la posición subordinada de las economías de los países en vía de desarrollo, entre los que se encuentra México, que incide directamente en las prácticas de alimentación, sobre todo de poblaciones vulneradas como son los trabajadores agrícolas, a pesar de emigrar a estados del país con mayores índices de desarrollo social y económico.

En Miguel Alemán, ubicado en una zona desértica en la cual se ha desarrollado una tecnología agrícola sofisticada, los alimentos de alta calidad producidos ahí están dirigidos a ciertos consumidores, mientras que las y los trabajadores que los cosechan son excluidos de su consumo, mecanismo que reproduce la subordinación histórica y estructura un campo alimentario en el cual prevalece la estratificación social de los alimentos.

El análisis sobre el campo alimentario entre una población vulnerada permite poner en el juego a los agentes y capitales que dan un sentido lógico a la práctica, y desnaturalizar así las decisiones alimentarias como un asunto individual. Permite comprender el entramado de relaciones sociales, económicas, históricas y políticas que ubican en posiciones distintas a los agentes sociales en relación con los capitales disponibles. Las y los jornaleros agrícolas migrantes son un sector productivo y poblacional en cuyas condiciones materiales y simbólicas de vida se reproducen diversas desigualdades, en detrimento de sus posibilidades para alimentarse y, con ello, los efectos a corto y largo plazo en la salud.

\section{Referencias}

Alcántara, Y. (2014). "A todo se acostumbra uno, menos a no comer... azúcar." Prácticas de alimentación ante la diabetes en grupos domésticos triquis, in- 
migrantes en Sonora (tesis de maestría). Recuperada de http://biblioteca. colson.edu.mx:8081/e-docs/RED/RED000942/index.html

Arancibia-Bulnes, C., Peón-Anaya, R., Riveros-Rosas, D., Quiñones, J., Cabanillas, R., y Estrada, C. (2014). Beam solar irradiation assessment for Sonora, Mexico. Energy Procedia, (49), 2290-2296. doi: 10.1016/j.egypro.2014.03.242

Aranda, P., y Castro, M. (2016). El campo de la agroindustria en el noroeste de México y la salud de sus jornaleras: una propuesta de estudio. Salud Colectiva, 12(1), 55-70. doi: 10.18294/sc.2016.878

Arellano Gálvez, M. C. (2018). Relaciones sociales y prácticas de alimentación de migrantes del sureste mexicano residentes en una comunidad agroindustrial de Sonora (tesis de doctorado inédita). El Colegio de la Frontera Sur, San Cristóbal de las Casas, Chiapas.

Arellano, M., Alvarez, G., Eroza, E., Huicochea, L., y Tuñón, E. (2019). Habitus alimentario: prácticas entre trabajadores agrícolas migrantes en una comunidad de Sonora, México. Salud Colectiva, 15:e1843. doi: 10.18294/ sc. 2019.1843

Atkins, P., y Bowler, I. (2016). Food in society: Economy, culture, geography. Nueva York: Routledge.

Barros, M. (2015). Apuntes sobre la vivienda para migrantes y crisis inmobiliaria en la California rural. Un estudio de caso. El Cotidiano, (191), 33-42.

Bautista, A. (2017). De ida y vuelta: vulnerabilidad y exclusión del mercado de trabajo a migrantes en los Estados Unidos y retornados en México en un contexto demográfico y migratorio dinámico. Geografares, (24), 132-144.

Beagan, B., Power, E., y Chapman, G. (2015). "Eating isn't just swallowing food": Food practices in the context of social class trajectory. Canadian Food Studies, 2(1), 75-98. doi: 10.15353/cfs-rcea.v2i1.50

Bourdieu P. (2008). El sentido práctico. Buenos Aires: Siglo XXI Editores.

Bourdieu, P. (2012). La distinción: criterios y bases sociales del gusto. México: Taurus.

Bourdieu, P., y Wacqüant, L. (2005). Una invitación a la sociología reflexiva. Argentina: Siglo XXI Editores.

Brunet, B., y Santamaría, C. (2016). La economía feminista y la división sexual del trabajo. Culturales, IV(1), 61-86.

Calvario, E., y Díaz, R. (2017). Al calor de la masculinidad. Clima, migración y normativas de género en la Costa de Hermosillo, Sonora. región y sociedad, (5), 115-146. doi:10.22198/rys.2017.0.a291

Carrillo, C. (2009). El origen del maíz. Ciencias, (92-93), 4-13.

Castañeda, J. (2017). Inseguridad alimentaria y obesidad en jornaleros agrícolas migrantes del estado de Sonora (tesis de maestría inédita). Centro de Investigación en Alimentación y Desarrollo (CIAD), Hermosillo.

Centro de Derechos Humanos de la Montaña Tlachinollan. (2011). La montaña de Guerrero, tierra de mujeres migrantes. México: Tlachinollan.

Chávez, A. (1999). La nueva dinámica de la migración interna en México 1970 1990. Cuernavaca: Ediciones Universidad Nacional Autónoma de México (UNAM) y Centro Regional de Investigaciones Multidisciplinarias.

Chong, E., Herrera, F., Chávez, C., y Sánchez, F. (2015). Mercado rural y precarización: nuevas condiciones socioeconómicas en el sur del Estado de México. región y sociedad, XXVII(63), 155-179. doi:10.22198/rys.2015.63.a240 
Comisión Nacional del Agua (CONAGUA). (2015). Estadísticas agrícolas de los distritos de riego año agrícola 2013-2014. México: Secretaría de Medio Ambiente y Recursos Naturales, CONAGUA.

Costa, S., Zepeda, L., y Sirieix, L. (2014). Exploring the social value of organic food: A qualitative study in France. International Journal of Consumer, 38(3), 228-237. doi: 10.1111/ijcs.12100

Criado, E. (2004). El valor de la buena madre: oficio de ama de casa, alimentación y salud entre las mujeres de clases populares. Revista Española de Sociología, (4), 93-118.

Criado, E. (2008). El concepto de campo como herramienta metodológica. Revista Española de Investigaciones Sociológicas, (123), 11-33.

Delgado, M. (2010). El sistema agroalimentario globalizado: imperios alimenticios y degradación social y ecológica. Revista de Economía Crítica, (10), 32-61.

Denzin, N., y Lincoln, Y. (2005). The Sage handbook of qualitative research. Thousand Oaks: Sage Publications.

Durand, J. (2017). Historia mínima de la migración México-Estados Unidos. México: El Colegio de México.

Escobar, A., Martin, S., Lowell, L., y Fernández, R. (2013). Estudio binacional sobre migrantes mexicanos en Estados Unidos y en México. Foreign Affairs Latinoamérica, 13, 12-17.

Espinoza, G., Ramírez, E., y Tello, A. (2017). Vivir, para el surco. Trabajo y derechos en el valle de San Quintín. México: Universidad Autónoma Metropolitana-Xochimilco.

Grammont, H., de, y Lara, S. (2004). Encuesta a hogares de jornaleros migrantes en regiones hortícolas de México: Sinaloa, Sonora, Baja California Sur y Jalisco. México: UNAM.

Gonzalez, G. (2016). Guest workers or colonized labor? Mexican labor migration to the United States. Nueva York: Taylor \& Francis.

Hammersley, M., y Atkinson, P. (1994). Etnografía. Métodos de investigación. México: Paidós.

Hernández, J. (2014). Condiciones de trabajo e ingreso en la agricultura intensiva mexicana. Análisis Económico, XXIX(71), 137-160.

Holmes, S. (2013). Fresh fruit, broken bodies: Migrant farm workers in the United States. Berkeley: University of California Press.

Instituto Municipal de Planeación (IMPLAN). (2016). Programa de Desarrollo Urbano del Centro de Población Miguel Alemán 2016. Recuperado de http: / /www. implanhermosillo.gob.mx/wp-content/uploads/2017/05/PDUMASEP2016.pdf

Izcara, S. (2014). La demanda de trabajadores huéspedes en la agricultura estadounidense. Cuadernos de Desarrollo Rural, 11(73), 149-169.

Joassart, P., Rossiter, J., y Bosco, F. (2017). Ethnic markets and community food security in an urban food desert. Environmental and Planning, 49(7), 16421663. doi: 10.1177/0308518X17700394

Kamphuis, C., Jansen, T., Mackenbach, J., y Lenthe, F., van. (2015). Bourdieu's cultural capital in relation to food choices: A systematic review of cultural capital indicators and an empirical proof of concept. PLoS ONE, 10(8). doi: 10.1371/journal.pone.0130695 
Kleider, H. (2015). Paid and unpaid work: The impact of social policies on the gender division of labor. Journal of European Social Policy, 25(5), 505-520. doi: $10.1177 / 0958928715610996$

Lara, S. (coord.). (2010). Migraciones de trabajo y movilidad territorial. México: Cámara de Diputados, Consejo Nacional de Ciencia y Tecnología, Miguel Ángel Porrúa.

Lara, S. (2012). Los territorios migratorios como espacios de articulación de migraciones nacionales e internacionales. Cuatro casos del contexto mexicano. Política y Sociedad, 49(1), 89-102.

Lara, S., y Sánchez, K. (2005). En búsqueda del control: enganche e industria de la migración en una zona productora de uva de mesa en México. En A. Riella y P. Macheroni (coords.), Empleo rural y asalariados rurales en América Latina (pp. 73-94). Montevideo: Consejo Latinoamericano de Ciencias Sociales.

Morais, P., da, Rocha, P., da, Carvalho, I., de, Fernandez, R., Dimitrov, M., Sabatini, F., Martins, P., y Baeza, F. (2014). Eating practices and habitus in mothers. A Brazilian population based survey. Appetite, 82(1), 16-28.

Morais, P., da, Gittelsohn, J., Fernandez, R., Roble, O., y Baeza, F. (2016). The use of Pierre Bourdieu's distinction concept in scientific articles studying food and eating: A narrative review. Appetite, (96), 174-186.

Moreno, J. (2006). Por abajo del agua. Sobreexplotación y agotamiento del acuífero de la Costa de Hermosillo, 1945-2005. Hermosillo: El Colegio de Sonora. Navarro, J., Robles, A., Vivoni, E., Montoya, J., Espindola, J., y Verduzco, V. (2018). Observed trends and future projections of extreme heat events in Sonora, México. International Journal of Climatology, 5168-5181. doi: 10.1002/ joc. 5719

Oncini, F., y Guetto, R. (2017). Cultural capital and gender differences in health behaviors: A study on eating, smoking and drinking patterns. Health Sociology Review, 27(1), 15-30. doi: 10.1080/14461242.2017.1321493

Ortega, I., Castañeda, A., y Sariego, J. (2007). Los jornaleros agrícolas invisibles productores de riqueza. Nuevos procesos migratorios en el noroeste de México. México: CIAD, Fundación Ford, Plaza y Valdés.

Ortega, I., y Alcalá, G. (2008). Pobreza, migración y seguridad alimentaria. En S. Sandoval, J. Meléndez (coords.), Cultura y seguridad alimentaria. Enfoques conceptuales, contexto global y experiencias locales (pp. 177-194). México: Plaza y Valdés.

Ortega I., Rosales C., Zapien, J., de, Aranda P., Castañeda, A., Saucedo, S., Montaño, C., y Contreras, A. (2012). Migration, agribusiness and nutritional status of children under five in northwest Mexico. International Journal of Environmental Research and Public Health, 9, 33-43.

Ortega, I., Rosales, C., Zapien, J., de, Aranda, P., Castañeda, A., Saucedo, S., Montaño, C., y Paddock, J. (2015). Invoking simplicity: “Alternative” food and the reinvention of distinction. Sociologia Ruralis, 55(1), 22-40. doi: 10.1111/ soru. 12056

Paddock J. (2016). Positioning food cultures: “Alternative” food as distinctive consumer practice. Sociology, 50(6), 1039-1055. 
Pérez, E. (2014). Los sobrevivientes del desierto. Producción y estrategias de vida entre los ejidatarios de la Costa de Hermosillo, Sonora (1932-2010). México: Bonilla Artigas Editores.

Pla, J. (2017). Trayectorias de clase y percepciones temporales sobre la posición ocupada en la estructura social. Un abordaje multidimensional de las clases sociales argentinas (2003-2011). Revista Internacional de Sociología, 75(3). doi: $10.3989 /$ ris.2017.75.3.16.05

Posadas, F. (2018). Mercado de trabajo de los jornaleros agrícolas en México. región y sociedad, XXX(72), 1-25. doi:10.22198/rys.2018.72.a885

Ramírez, M. (2002). El efecto del proceso de migración en el estado nutricio de familias jornaleras migrantes en el noroeste de México (tesis de maestría inédita). CIAD, Hermosillo.

Reyes, A., y Quintero, M. (2009). Problemática del agua en los distritos de riego por bombeo del estado de Sonora. Revista Digital Universitaria, 10(6), 1-19.

Rojas, T. (2017). Migración rural jornalera en México: la circularidad de la pobreza. IberoForum, XII(23), 1-35.

Salazar, A., Moreno, J., y Lutz, A. (2012). Agricultura y manejo sustentable del acuífero de la Costa de Hermosillo. región y sociedad (3), 155-179. doi:10.22198/rys.2012.3.a411

Sánchez, K., Saldaña, A., y Lara, S. (2018). ¿Dónde comienza la (in)sostenibilidad social de un enclave agrícola de producción de uva de mesa en Sonora, México? AGER. Revista de Estudios sobre Despoblación y Desarrollo Rural, (24), 95-122.

Secretaría de Desarrollo Social (SEDESOL). (2013). Indicadores de marginación. México: SEDESOL. Recuperado de http://www.microrregiones.gob.mx/catloc/indiMarginacLoc. aspx? refnac $=260300343$

Secretaría de Desarrollo Social (SEDESOL). (2015). Informe anual sobre la situación de pobreza y rezago social 2015. Hermosillo, Sonora. México: SEDESOL. Recuperado de https://www.gob.mx/cms/uploads/attachment/file/46482/ Sonora_030.pdf

Secretaría de Desarrollo Social (SEDESOL). (2016). Cruzada Nacional contra el Hambre. México: SEDESOL. Recuperado de https: / /www.gob.mx/sedesol/acciones-y-programas/cruzada-nacional-contra-el-hambre-18938

Secretaría de Desarrollo Social (SEDESOL). (2018). Informe anual sobre la situación de pobreza y rezago social 2018. México: SEDESOL. Recuperado de https://www.gob.mx/cms/uploads/attachment/file/288969/Sonora.pdf

Taylor, S., y Bogdan, R. (1994). Introducción a los métodos cualitativos de investigación. La búsqueda de significados. Barcelona: Paidós Básica.

Valdés, X. (2015). Feminización del empleo y trabajo precario en las agriculturas latinoamericanas globalizadas. Cuadernos de Antropología Social, (41), 39-54.

Valdez, J. (2012). Alimentación, cultura y estado nutricional en jornaleros agrícolas migrantes en un campo de la Costa de Hermosillo (tesis de maestría inédita). CIAD, Hermosillo.

Valdivia, M. , y Sánchez, L. (2017). Protección laboral para los jornaleros agrícolas en México. Apuntes para la Equidad, (3), 1-4. 
Vargas, L. A. (2002). La alimentación de los criollos y mestizos en el México colonial. En D. Alarcón Segovia y H. Bourges Rodríguez (eds.), La alimentación de los mexicanos (pp. 47-66). México: El Colegio Nacional.

Velasco, L. (2013). Escuela y reproducción social de familias migrantes: hijos e hijas de jornaleros indígenas en el noroeste mexicano. Estudios Demográficos y Urbanos, 28(82), 189-218. doi: 10.24201/edu.v28i1.1443

Velasco, L., Zlolniski, Ch., y Coubès, M. (2014). De jornaleros a colonos: residencia, trabajo e identidad en el valle de San Quintín. Tijuana: El Colegio de la Frontera Norte.

Villa, A., y Bracamonte, A. (2013). Proceso de aprendizaje y modernización productiva en el agro del noroeste de México: los casos de la agricultura comercial de la Costa de Hermosillo, Sonora y la agricultura orgánica de la zona sur de Baja California Sur. Estudios Fronterizos, 14(27), 217-254.

Wills, W., Backett-Milburn, K., Roberts, M., y Lawton, J. (2011). The framing of social class distinctions through family food and eating practices. The Sociological Review, 59(4), 725-740. doi: 10.1111/j.1467-954X.2011.02035.x 